\title{
Log Rolling as an Explanation of Distortions All Round: A Model à la Buchanan and Tullock
}

\author{
William Coleman ${ }^{1}$
}

\section{Introduction}

Since at least the time of Adam Smith, economists have been alive to the vision of a relatively small number of 'special interests' benefiting themselves at the expense of the public weal. But distortions are today so endemic, it is tempting to say that every interest manages to secure that status of special interest, and receives some 'distortion' in its favour. But, however credible this scenario of 'universal distortions' may be, can it be provided a rigorous and well-articulated modelling in terms of maximising choices, under a specified institutional structure? Can Public Choice suggest such a modelling? Can, in particular, the Public Choice theorising of ' $l o g$ rolling' do so?

It is argued here that the Public Choice theorising of log rolling (Buchanan and Tullock 1962) can provide such a rationalisation, as its framework can be stretched to admit the possibility of 'distortions all round'. The word 'stretch' is used advisedly: the unhappy possibility of 'distortions all round' is perhaps unrepresentative of the more optimistic bent of the Public Choice theory of log rolling. Yet, the pessimistic possibility still has value as a corrective to the overly hopeful account that Buchanan and Tullock originally provided of log rolling.

1 The Australian National University, william.coleman@anu.edu.au. 


\section{An Australian illustration of universal distortions: 'Protection all round'}

Australian experience of the twentieth century resonates with the vision of universal distortions expounded in the introduction.

The advent of the new Commonwealth of Australia in 1901 was followed by a spreading inhibition of competition. This began with the establishment of a national tariff wall for manufacturers; first of low height but later inexorably increasing. This tariff quickly saw the attempt by labour unions to encumber competition in the labour markets of protected industries, under the banner of New Protection. Though initially unsuccessful, the regulation of the labour market quickly swelled, and a sense of quid pro quo between labour and manufacturers certainly added charge to the surge.

The sudden emergence of the Country Party at the close of the First World War may have been expected to menace this exchange between urban capital and labour, as the agricultural interest was injured by tariffs on manufactured importables. But the admission of the Country Party to the cabinet room in 1922 saw no moderation in the now 'settled policy of Protection'. The relevant Act was simply revised to require the Tariff Board to include representatives of the rural interest. Thus, the farming sector had joined the club, and a stifling of competition in agriculture ensued. This was sometimes through tariffs and bounties (e.g. sugar), but also through 'marketing boards': first for fruit in the interwar period, then wheat in the post-Second World War period, and finally (and most catastrophically) for wool for about 20 years from the 1970s. The untiring partisan of this last disastrous piece of competition restriction was Jack McEwan, who was very briefly prime minister in 1960s but (de facto) deputy prime minister from 1958 until 1971. As industry minister, he was the epitome of the creed of 'Protection All Round'. Such protection would be conferred not only on import competitors, but also exporters through export subsidies ('export incentives'). Whoever you were, there was a tariff or bounty for you. $^{2}$

How might a 'log rolling' explain, or rationalise, such a universal schema of distortion?

2 Ramsey Macdonald, Prime Minister of Great Britain 1929-1935, caught the dynamic in his statement of 1908: 'The Australian system is Protection, Wages Boards, Prices Boards, more Prices Boards—round and round and round' (quoted in Marsh 1988). 


\section{The Buchanan and Tullock model of log rolling}

Log rolling is the trading of favours by sectional interests. Thus, the timber interest supports a tariff on sugar, in return for the sugar interest supporting a tariff on timber. ${ }^{3}$ The thought easily arises that 'protection all round' might arise from a universal log rolling. But does 'theory' give grounds for supporting this notion?

In their The Calculus of Consent (1962) James Buchanan and Gordon Tullock $(\mathrm{B} \& \mathrm{~T})$ present a theoretical analysis of log rolling. In concrete terms, B\&T model a legislature's decisions to impose taxation and to allocate consequent revenue between rival interests. To schematise B\&T's analysis, we will imagine a society composed of communities of distinct interests; 'towns' if you like, which will be named here A, B, C, etc. ${ }^{4}$ Each town obtains a distinct benefit from some capital expenditure that is not (readily) supplied by the market. We can think of this as a 'road'. We assume each town benefits from its own road only, and none at all from the roads to other towns. This is important: interests are distinct and rival. ${ }^{5}$

The benefit to any given town of its road is an increasing function of its size in $\mathrm{m}^{2}$ (see Figure 1).

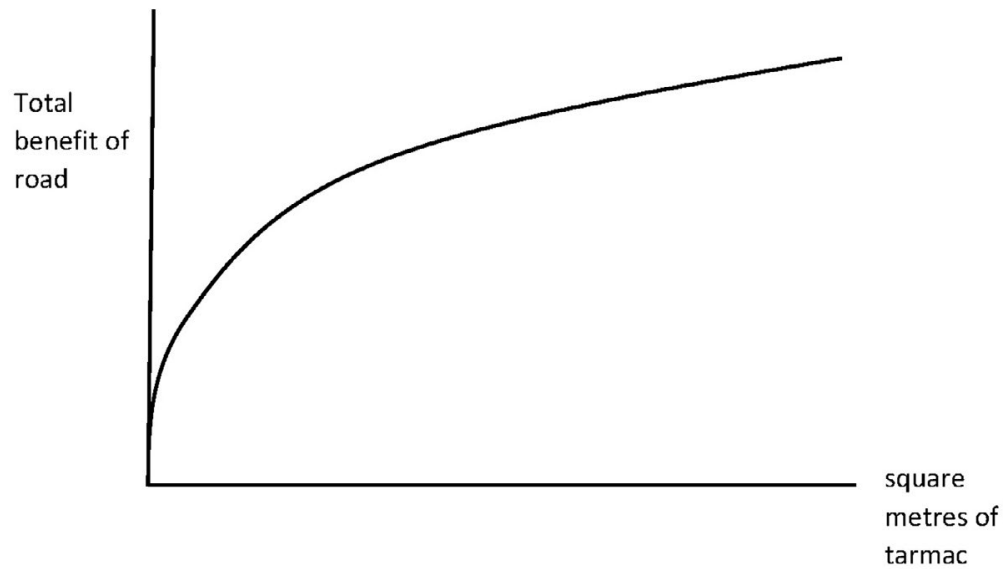

Figure 1: Benefit of road of representative town as a function of its size

3 See the classic study of the Smoot-Hawley Act by Schattschneider (1935). See also Irwin and Kroszner (1996) for strong quantitative evidence that in that Act logs were rolled between lumber and oil interests.

4 B\&T call the decision-makers 'farmers'. A more substantive deviation of this paper's schematisation from B\&T lies in the considerable attention B\&T give to what they call 'Kantian' decision heuristics: where each decisionmaker 'does unto others as he would do unto himself'. This comes down to each farmer voting for that common length road throughout the community that would maximise his benefit. Such a decision heuristic would yield as an equilibrium that common length of road that would be most preferred by the median farmer. The present paper ignores this heuristic.

5 At the opposite extreme, we could assume each town places some (probably town-varying) value on some common road. We would then be in the terrain of the well-known median voter model, and the median town would rule the roost. The median voter is certainly a more plausible model for generally desired public goods, and infrastructure whose costs are principally fixed rather than variable (transoceanic cables?). 
Roads are also costly. We shall, for simplicity, assume a road is a linear function of its length (see Figure 2).

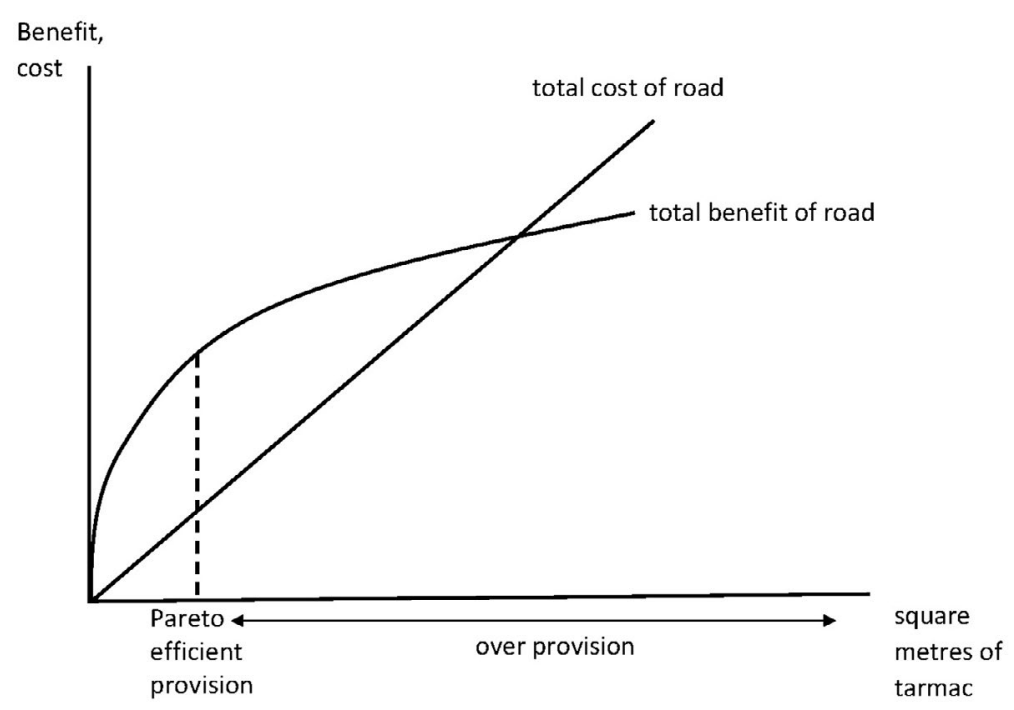

Figure 2: The Pareto efficient amount of road

The decision to build any road is made by the majority vote of a legislature of $\mathrm{N}$ members, where each town elects one member.

It is also assumed that any decision to build a given road must be accompanied by a revenue measure to pay for it. Thus, every dollar of tax revenue is 'hypothecated' to some particular expenditure. Thus, the total tax burden consists of an array of purpose-dedicated taxes: a 'road for A' tax, a 'road for B' tax, etc. ${ }^{6}$ A key further assumption is that, as a matter of constitutionality, each such hypothecated tax must be directly borne by the whole of society: so all $\mathrm{N}$ towns will pay a 'road for A' tax. Reinforcing that provision, we assume there can be no 'side payments' between the towns, either through the fiscal system or privately.

The critical upshot of these assumptions about financing is that any town pays only a fraction of the cost of its own road. So, assuming $\mathrm{N}=5$ (A, B, C, D and E), each town only pays 0.2 of the total cost of the road, and only pays 0.2 of the cost of an extra square metre of its road.

6 The deadweight losses of a given tax may be included as part of the cost of the road. 


\section{The 'Nash game' outcome}

Suppose each town chooses its vote taking the votes of the other towns as given. It is not difficult to see that whatever the constellation of votes of the other towns, it is always 'dominating' for any given (self-interested) town to vote against all roads but its own. ${ }^{7}$ The upshot of the 'Nash game' logic, then, is there would be no roads at all, as every road bill is voted down four to one. ${ }^{8}$

\section{A vote-trade outcome}

Now consider this set of votes.

A votes for B's road. B votes for A's.

$B$ votes for C's road. C votes for B's.

C votes for D's road. D votes for C's.

D votes for E's road. E votes for D's.

E votes for A's road. A votes for E's.

This vote set is perhaps more easily represented in the diagram in Figure 3.

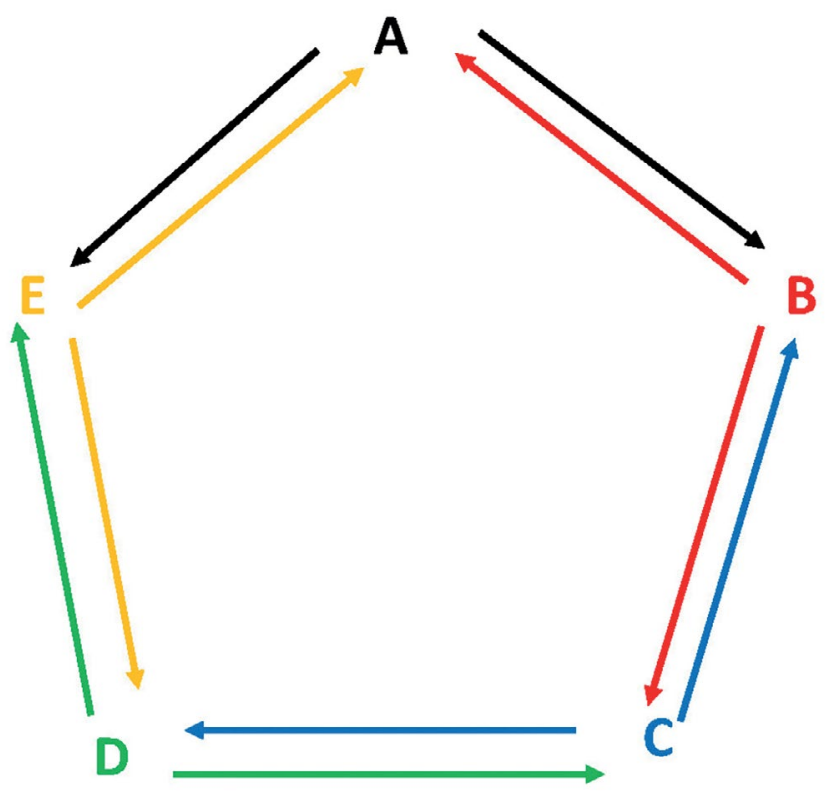

Figure 3: A comprehensive vote-trade of five towns

7 This is true no matter how small a number constitutes a majority: two, for example.

8 This conclusion rests on an assumption that all towns 'act Nash'. As previously noted, B\&T explore the implications of a town acting 'Kantian', and following a 'Do unto others as you do unto yourself' precept. They stress that if a majority of towns are Kantian, some roads will be built, despite a 'Nash' minority. 
Each town receives three votes for its road (including its own), and so each town has a road built.

How could this constellation of votes come about? It is not, of course, the outcome of a 'Nash game'. Under a 'Nash game' logic, each town would only vote for its own road. But in the constellation of voting instanced above that would seem to be foolish conduct, because, for example, A can hardly expect B will vote for A's road once A doesn't vote for B's. This pattern of votes, then, seems to be construable as trades_-vote trades: 'I will vote for your road in return for you voting for mine.' To illustrate specifically in the context of five towns, if a town is to have a road, it needs two votes in addition its own; it acquires those votes by voting in favour of two other towns' roads.

\section{Buchanan and Tullock's thesis and some justifications}

B\&T contend that if benefits and costs are symmetric and the number of towns is five, then the vote trades result in each town having a road built such that $\mathrm{mb}=0.6$ mc, as illustrated in Figure 4.

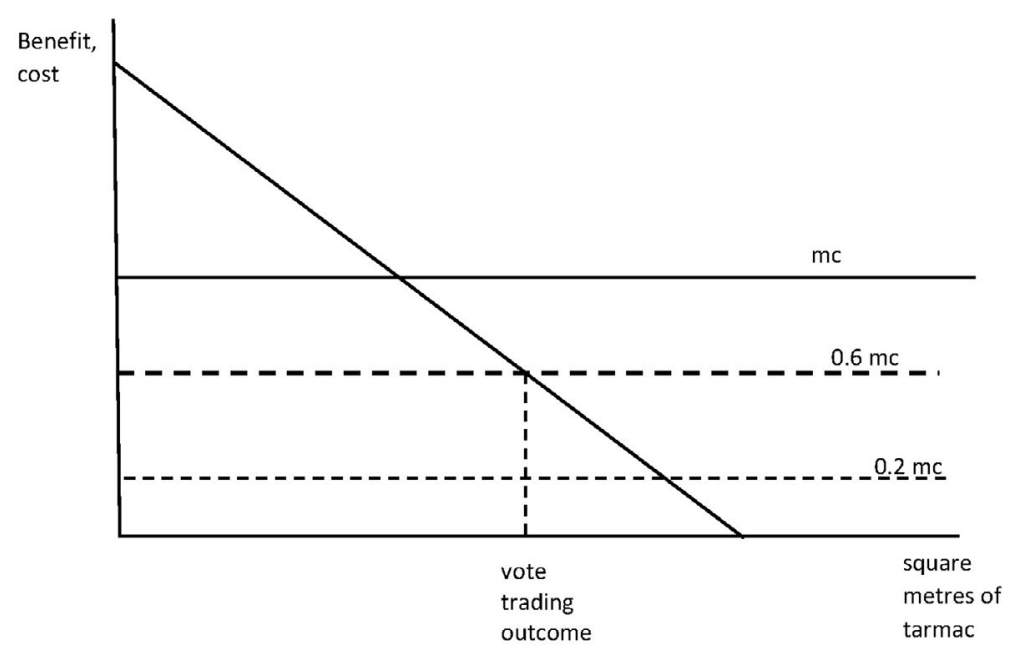

Figure 4: Rolling the logs à la Buchanan and Tullock

The contention seems plausible. If $A$ wishes to acquire another mile of road, it needs to vote for another mile of road for two other towns. Thus another mile for A requires another three miles in total; and, as the costs are shared among five towns, the marginal cost to A of the extra mile of road is 0.6 of its actual marginal cost. 
Another route to the B\&T contention would begin with the case where a 'majority' is deemed not to be three votes out of five, but just one vote (see Figure 5). There is no vote trading, but given the requirement that only a single vote is sufficient to pass a road bill, it is evident each of the five roads will be built until the marginal benefit of each is 0.2 of its mc for each town. ${ }^{9}$

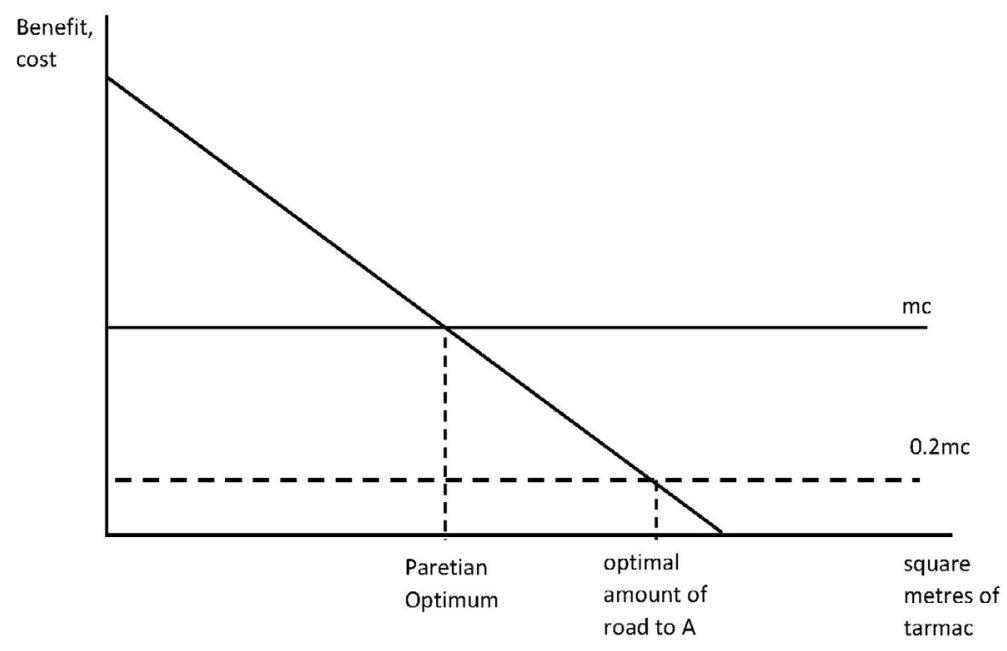

Figure 5: With only one vote required, the actual length of each town's road is each town's most preferred length

If a 'majority' is deemed to consist of just two votes, a vote trade can be construed as a bargain between two towns over the total outlay on their two roads, along with its allocation. Both the 'coalitions' analysis of game theory (that B\&T invoke), along with widely used bargaining models (e.g. Zeuthen and Nash) imply that 'the bargain' will maximise the product of the payoffs; with symmetric benefits, roads will be built until $\mathrm{mb}=0.4 \mathrm{mc} .{ }^{10}$ The case of three votes—-that is, a genuine majority with five towns - would be a simple generalisation: the maximisation of the product of three net payoffs under symmetric benefits and costs producing $\mathrm{mb}=0.6 \mathrm{mc} .{ }^{11}$

9 Even though there is no public good here, the structure of this situation seems very like the well-known Public Goods game, but in reverse. At $\mathrm{mb}=0.2 \mathrm{mc}$, any unilateral reduction in road length by one town would make four towns better off, but the unilateral reducer worse off. So, no one unilaterally reduces.

10 In both Zeuthen and Nash, the maximand is the product of the net benefit of the involved parties. Let the gross benefit of road of length $\mathrm{L}_{\mathrm{i}}$ to town $\mathrm{i}$ be $\mathrm{G}\left(\mathrm{L}_{\mathrm{i}}\right)$. Thus for towns $\mathrm{A}$ and $\mathrm{B}$ the product of net benefits equals $\left[G\left(L_{A}\right)-0.2 c\left[L_{A}+L_{B}\right]\right]\left[G\left(L_{B}\right)-0.2 c\left[L_{A}+L_{B}\right]\right]$. This is a maximand in $L_{A}$ and $L_{B}$. The first order condition with respect to $\mathrm{L}_{A}$ is $\left[\mathrm{G}\left(\mathrm{L}_{A}\right)-0.2 c\left[\mathrm{~L}_{A}+\mathrm{L}_{B}\right]\right][-0.2 c]+\left[G\left(\mathrm{~L}_{B}\right)-0.2 c\left[\mathrm{~L}_{A}+L_{B}\right]\left[G^{\prime}\left(\mathrm{L}_{A}\right)-0.2 c\right]=0\right.$. The condition with respect to $L_{B}$ is symmetrical. The two conditions taken together imply $G^{\prime}\left(L_{A}\right)=0.4 c=G^{\prime}\left(L_{B}\right)$.

11 This rationalisation assumes the vote trade is a trilateral bargain: so $\mathrm{A}, \mathrm{B}$ and $\mathrm{C}$ all agree to vote for roads for $\mathrm{A}$, $\mathrm{B}$ and C. However, such a bargain would mean D and E are 'left over'. One solution is many trilateral trades, each of which only partly funds a given road. In the five-town case, there are 10 possible trilateral combinations: $\mathrm{ABE}$, $\mathrm{BCA}, \mathrm{CDB}, \mathrm{DEC}, \mathrm{EAD}, \mathrm{ADC}, \mathrm{ACE}, \mathrm{DEB}, \mathrm{ABD}, \mathrm{EBC}$. Thus, Road A can be funded by six trilateral bargains$\mathrm{ABE}, \mathrm{BCA}, \mathrm{EAD}, \mathrm{ADC}, \mathrm{ACE}, \mathrm{ABD}$ - each providing one-sixth of the total funding. (And symmetrically for the four other towns.) 
The upshot is that all five towns have their road built, of a length such that the benefit of an extra mile of road is 60 per cent of its costs.

\section{The significance of the possibility of defection}

But is there not a fly in the ointment? Why are all five towns linked in voting, such that each town is in at least one majority vote with every other town? ${ }^{12}$ Would it not be improving for, say, B, C, D and $\mathrm{E}$ to strike a vote trade amongst themselves that completely excludes A (see Figure 6). B, C, D and E still have their road, but with only four roads in total, B, C, D and $\mathrm{E}$ have less taxes to pay.

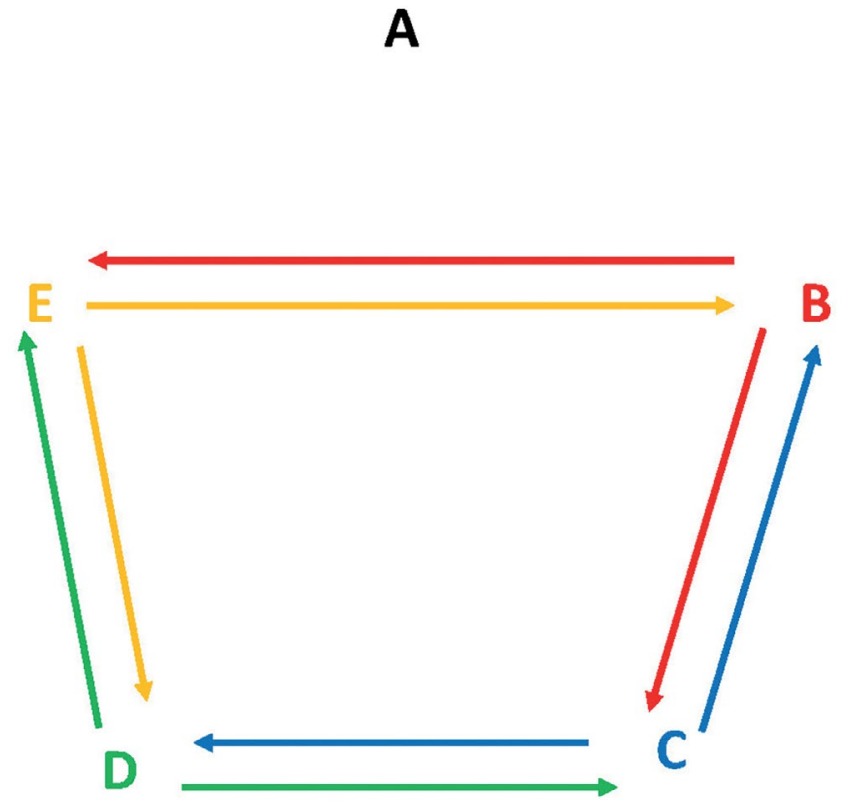

Figure 6: A defection of four

A, of course, would be worse off. And this observation is fuel for an argument that this defection would not be an equilibrium. For A could go to B, C and D and say 'Include me and drop E. You will benefit as I will ask for an epsilon smaller road than $\mathrm{E}$ is receiving'. But obviously $\mathrm{E}$ could get 'back in' by saying to $\mathrm{ABC}$, 'Include me and drop D. You will benefit as I will ask for an epsilon smaller road than D'. But D could go to EAB and say 'Include me and drop C ...' 'Cycling', then, appears to be the consequence of 'playing fours'. ${ }^{13}$ If we are to take this cycling quite

12 Thus, $\mathrm{A}$ is in two majority votes with $\mathrm{B}$, two with $\mathrm{E}$, once with $\mathrm{C}$ (in voting together for B's road) and one with $\mathrm{D}$ (in voting together for E's).

13 It might be argued that B, C, D and E will anticipate the destructive effects of A's attempts to get in and substitute themself for one of the four, and consequently refuse A's offer. But B knows that if he, for example, refuses A, C may accept A. 
literally, a given town will receive only four-fifths of the benefits it would have under comprehensive vote trading, as its misses out on a road once every five times in a cycle. But it is equally true that a given town's tax burden will be only four-fifths of that it would have without cycling (as total roads have been reduced by one-fifth). So the cycle that would seem to arise from 'playing fours' brings a town only fourfifths of net benefits of 'playing fives'. Defection, it would seem, is not advantageous.

The conclusion that defection is not advantageous does not require cycling to literally arise from defection. ${ }^{14}$ The same conclusion will flow from a 'musical chairs' modelling of defection, where the deal-making of towns is unpredictably brought to a halt, with four in a defecting coalition and one outside; with each town hoping not to be the one without a chair to sit on (i.e. left out of the four) when 'the music stops'. Each faces a one-in-five chance that it will be left so. Evaluating outcomes in terms of their mathematical expectation leads to the same conclusion: trying to 'play fours' reduces net benefit relative to fives. By the same sort of argument, the same conclusion applies to any attempt to 'play threes'.

Thus, it would seem irrational for anyone to try to organise a defecting coalition. But this conclusion rests on an implicit assumption: the net benefit of comprehensive vote trading ('playing fives'), relative no vote trading at all, is, indeed, positive. But the net 'benefit' of playing fives may be negative! Our assumptions allow the possibility that a road built until its marginal benefit is 60 per cent of its marginal cost will cost more than the benefit it provides (see Figure 7). We will call this 'ultra overprovision'.

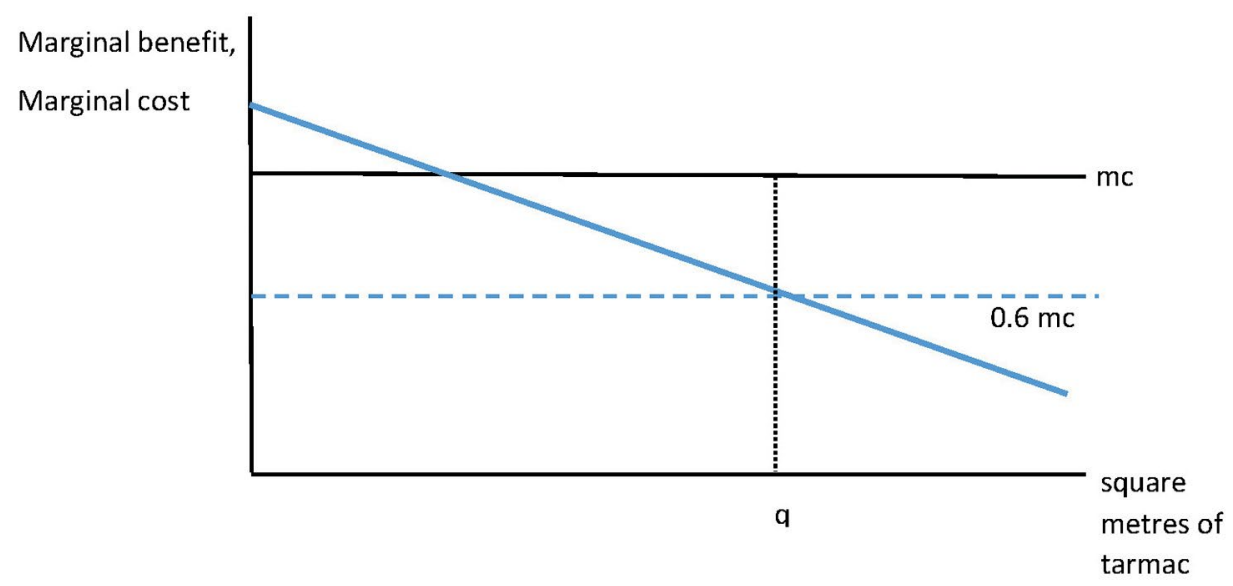

Figure 7: Ultra overprovision

The area under the marginal benefit curve (up to q) is less than the area under mc curve.

14 A literal modelling of cycling implicitly requires the clunky assumption that the number of periods in the model is at least equal to the number of towns. What if the model was a one-period model? 
Indeed, our assumptions allow the possibility that a road of any positive length will cost more than the benefit it provides. This last possibility we will dub 'roads as bads' (see Figure 8).

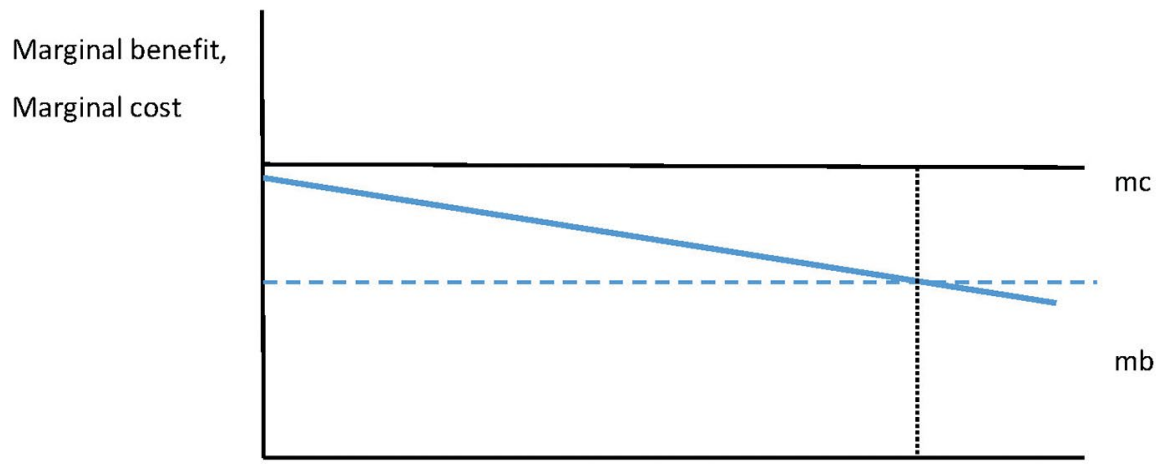

square metres of tarmac

Figure 8: Roads as bads

We conclude that if roads are bads, or are 'ultra overprovision' liable, defection will take place, as defection reduces the loss each town experiences relative to comprehensive vote trading. Thus, if roads are bads, then roads will not be universally provided; instead, a coalition of fewer than five towns will provide roads for coalition members only. The composition of that coalition is random and will be replaced by another coalition, of equally unpredictable composition, in the succeeding period.

\section{Log rolling and distortions all round}

So, to what extent does the analysis of log rolling of roads confer any warrant on 'distortions all round' as an outcome of democratic legislative processes?

\section{Pandering all round}

Under comprehensive vote trading - the situation where roads bring more benefits than costs-each road is overprovided, in the sense that benefit of the last mile is 40 per cent less than its cost. ${ }^{15}$ Thus, there would be an actual pareto improvement for every town, if every town's road was reduced in length. It is a common complaint that democratic processes will 'pander to', or indulge, a minority. We see that in the B\&T model 'we are all pandered to', as we are all a member of some minority

15 There seems to be a fairly obvious reference here to a federal political system in which all tax is derived at the federal level, and where 'states' figure for 'roads'. 
(some 'town'). And we are all worse off than if we were not so greatly pandered to. This situation might also be put in terms of the language of 'exploitation', which we take to mean as any policy that has a winner, but the winner(s) cannot compensate the loser(s) and remain winners. In other words, a policy that provides a private benefit, but at a social cost. In B\&T we are all exploiting all others-we all receive benefits that come at a social cost. But, at the same time, we are all being exploited by others.

This dismal scenario seems resonant of the Distortions All Round. And yet, the scenario doesn't truly match such a problem. The problem in B\&T is overprovision ('overactivity') by the state. But the paper has concluded that-putting aside 'roads as bads', and the possibility of 'ultra overprovision'-comprehensive vote trading implies that each town is still better off on account of the road that is built compared to having no road at all; each town is better off from the consequences of this vote trading and the concomitant construction. Thus, B\&T is not capturing the situation where the government would do best, by tenets of standard theory, to leave well alone entirely. Thus, the B\&T model apparently cannot be referring to government interventions that are simply 'distortions'. On the face of it, nothing here in B\&T rationalises 'distortions all round'.

But what of the situation where the marginal benefit of roads is so low-extending to the case where roads are bads-where (we have concluded) the community as a whole is made worse off by the vote trading that does occur, relative to a benchmark of no legislative activity and no roads at all (see Figures 7 and 8). This situation seems relevant to 'protection all round' etc. because all distortions are, necessarily, 'bads'. In fact, it is easy to see that reworking the analysis of the previous section with outright distortions will simply replicate the case of roads as bads. Consider the situation where, instead of roads, the legislature may grant a transport subsidy to any town: a sum of money earmarked to be used for subsidising the cost of transport. The key schedules are indicated in Figure 9. Notice the mb of the subsidy is always less than the mc of the subsidy; this is necessarily so by the nature of a distortion (and reflects the deadweight loss of the taxation to raise the revenue for the subsidy, as well as the distortion of choices induced by the subsidy).

Since the area under the $\mathrm{mb}$ curve (at quantity $=\mathrm{g}$ ) exceeds 60 per cent of the cost of quantity $g$ (i.e. the rectangle abgd), the logic of log rolling would seem to spell 'distortions all round'. 


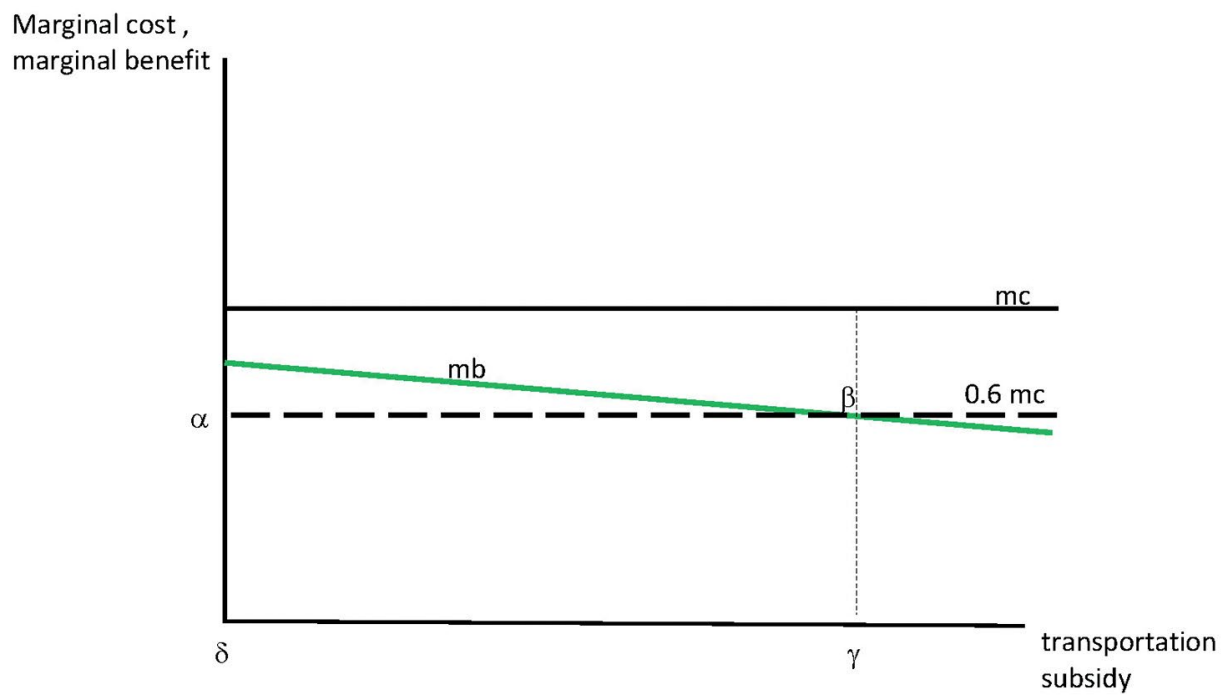

Figure 9: By log rolling, every town receives a transport subsidy?

But, as the analysis of roads as bads has prefigured, the fact that total net benefit to the community of such road building must now be negative implies that 'distortions all round' (i.e. distortions to all five towns) will not be an equilibrium. Rather, as defection into an excluding coalition now pays off in expectational terms, in each period an (unpredictable) majority would impose distortions ('roads') in their favour only. ${ }^{16}$ This doesn't look like the 'distortion all round' observed historically. History has not been a melee of successive coalitions leaving a minority out in the cold. It has not been a game of 'pass the parcel' among players (where the parcel wraps 'no distortion'). We conclude that the B\&T model thus far construed offers no rationalisation of that phenomenon.

\section{Risk aversion as a route to distortions all round}

To rehearse the conclusions above: if the policy at issue is a distortion (roads as bads), then the mathematical expectation of the benefit of defection from comprehensive (five-town) vote trading, in an attempt to form an excluding coalition, is positive. Therefore, if the policy at issue is a distortion, there will be defection from comprehensive vote trading and there will not be 'distortions all round'.

This conclusion, however, has been established by implicitly assuming risk-neutrality in evaluating the two possible payoffs from playing 'excluding coalition' when roads are bads: positive if you are inside that coalition, negative if you are outside it.

16 Since all roads are welfare reducing, and as the (negative) 'benefit' of roads is equally shared through cycling, it is improving for all to reduce the number of towns building them. 
Clearly, with a sufficiently large degree of risk aversion, the negative payoff that a town risks by playing 'excluding coalition' (that is, ending up the meat in the vote-trading sandwich of other towns) may outweigh the positive payoff possibility (i.e. other towns being the meat). Thus, with a sufficiently large degree of risk aversion, defection from comprehensive vote trading becomes, by utility calculus, no longer advantageous. And, in consequence, there is comprehensive 'distortions all round'.

To summarise: we seem to have finally caught sight of how it may be that distortions all round can come to pass. Each town prefers the predictable mediocrity of distortions all round to the possibility of being dudded themselves in a struggle to dud other towns.

It would seem, then, that risk aversion makes possible 'distortions all round' by log rolling.

But how substantial is this possibility? Not much can be said in answer, beyond registering 'distortions all round' by log rolling does require a 'sufficient degree' of risk aversion. This 'sufficient degree' may not occur. But we can simply describe the circumstances when any degree of risk aversion is more likely to be 'sufficient'. Recall that 'distortions all round' occurs where defecting into an excluding coalition is a gamble that has a negative impact on expected utility, in spite of the positive mathematical expectation of its payoffs. Clearly, the more positive the mathematical expectation of payoffs, the less likely that the impact of defection on expected utility will be negative. Recall the positivity of the mathematical expectation of payoffs from defecting simply reflects the fact that we are dealing with distortions; things the reduction of which will yield a social benefit. Thus, the worse the social cost of the distortion, the more the positive mathematical expectation of payoffs to defecting. Thus, the worse the social cost of the distortion, the less likely the impact on expected utility from defection will be negative; and the more likely defection will dominate distortions all round. Distortion all round seems, then, to be a symptom of mild cases of the distortionary disease at hand, not severe cases. The less distortionary the distortion-the less serious the distortion at issue-the more likely it becomes that it is (alas) spread all round.

\section{Review}

This paper set itself the task of discovering if B\&T schema's of universal log rolling could rationalise a situation of universal distortions. The answer, in brief, is yes, with 'sufficient equipment' that peak can be scaled.

The most specific piece of the requisite equipment is a 'sufficiently strong' degree of risk aversion. 
But beyond that, a great deal of paraphernalia has been used, as the B\&T model is a very specific, assumption-ridden model. Assumptions of the B\&T model include:

'Direct democracy'. There are no politicians, as distinct from voters.

A legislature, but no executive. There is no prime minister, president, chancellor or cabinet chosen by the legislature that assumes control of the legislative process, or reduces any legislation it does not support to 'private members' bills'.

A legislature, but no parties. There is no 'aggregation of interests' into a few parties that contest control of the legislature. Each town is a party of one.

Cost sharing is exogenous. Side payments are assumed away.

Each interest has the same number of seats. This need not be taken literally-the key assumption is better stated as 'a majority of interests always constitutes a majority of the legislature'. Thus, if there were 99 seats and five interests, a distribution of seats across the five interests of $27,21,19,18$, and 13 would satisfy this. This still amounts to a great deal of structure: of the $\mathrm{N}$ interests it is assumed that any of these can pass laws with the aid of any N/2 of the others, but not with fewer than N/2 of any others.

No possibility of constitutional remedy is admitted. In the present paper's schematisation of B\&T analysis, towns are not able to contract with each other. By contract, I mean 'make an agreement that, once struck, leaves no opportunity to break it'. Or, in more economical terms, make an agreement such that the penalty for violation is so large it would never be violated. ${ }^{17}$ All the vote trades in this paper's schematisation are sustained only by implicit mutual consent, which lacks any enforceability. ${ }^{18}$ If the towns could truly contract, then in the case of distortions all round (with roads as bads), they would surely contract to not have any roads, because the expected net benefit of each town is negative. Such a contract could be a constitutional amendment to ban any 'road' building.

Yet, for all the above equipment needed to reach the paper's conclusion, the conclusion remains significant. In the $\mathrm{B} \& \mathrm{~T}$ rationalisation of 'distortions all round', distortions are pervasive despite the complete absence of considerations that economists often think are key to the emergence of distortions.

17 These penalties might be external (arising from the courts), or they could be a matter of internal sanction ('my word is my bond'; the gentleman's agreement). The source of enforceability doesn't make any difference here. 18 The best example of this 'consent without enforceability' is from workplace relations: where neither union nor employers are in any contractual relation, but each has the strike or lockout tool, respectively. The (implicit) mutual consent to the wages and profits that are paid lies in there not being a strike or lockout. 
First, in the B\&T model no interests are special in their nature-no factor is concentrated in ownership relative to others, or enjoys an abundance of alternative uses that others do not possess, or has private information. And yet distortions are still possible; universal ones, indeed.

Second, in the B\&T rationalisation of distortion all round, no interests are privileged with respect to the policy formation-another common suspect in explaining distortions. No one in the B\&T analysis has any 'connections'; no one has any inside track with legislature.

Thus, the present analysis casts a bleaker light on democracy than that which B\&T were shining in 1963. For, to B\&T, the significance of log rolling extended far beyond the mutual back-scratching of vested interests in the drafting of tariff legislation. At the most abstract level, the B\&T analysis amounted to a reconceptualisation of the nature of democracy. Democracy, their analysis of log rolling taught, is not the articulation of some 'will of the people'; it is a system of competitive political exchange. And just as we have reason to believe that economic exchange is actual Pareto improving, so too, taught B\&T, is political exchange. Their analysis of log rolling was in some ways an epitomisation of the Public Choice outlook of being wary of government, but trustful of democracy.

That trust is obviously not broken by the few pages of analysis above, but that analysis does, sadly, serve its erosion.

\section{References}

Buchanan, J.M. and Tullock, G. 1962. The Calculus of Consent: Logical Foundations of Constitutional Democracy. Ann Arbor: University of Michigan Press. doi. org/10.3998/mpub.7687

Irwin, D.A. and Kroszner, R.S. 1996. 'Log-rolling and Economic Interests in the Passage of the Smoot-Hawley Tariff, Carnegie-Rochester Conference Series on Public Policy 45, 173-200. Prepared for the Carnegie-Rochester Conference on Public Policy, Pittsburgh, PA, 10-11 November 1995. doi.org/10.3386/w5510

Marsh, I. 1988. '1888 Revisited: The Prospects for Australian Political Realignment'. Australian Graduate School of Management Working Paper 88-006, University of New South Wales, Kensington.

Schattschneider, E.E. 1935. Politics, Pressures and the Tariff: A Study of Free Private Enterprise in Pressure Politics, as Shown in the 1929-1930 Revision of the Tariff. New York: Prentice-Hall. 
This text is taken from Agenda, Volume 24-Number 1, 2017, edited by William Coleman, published 2017 by ANU Press, The Australian National University, Canberra, Australia.

dx.doi.org/10.22459/AG.24.01.2017.03 